\title{
Sobre la des-restauración. Los límites de intervención en el patrimonio arquitectónico a debate en el IAPH
}

Convocada a instancias de la Academia del Partal, Asociación Libre de Profesionales de la Restauración Monumental, y organizada por el Instituto Andaluz del Patrimonio Histórico (Dirección General de Bienes Culturales, Consejería de Cultura de la Junta de Andalucía), entre los días veintitrés y veinticinco del pasado mes de noviembre, se desarrolló en Sevilla la III Bienal de Restauración Monumental.

\section{Entender la intervención arquitectónica sobre el patrimonio como acto creador y, al mismo tiempo, la necesidad de restringirla fue uno de los temas de discusión}

Bajo el lema Sobre la des-Restauración, se proponía a los convocados reflexionar acerca de este neologismo en el campo de la conservación científica del patrimonio construido, entendido hasta ahora como el acto de eliminación de intervenciones de restauración-conservaciónaportación reciente, desde supuestas teorías o principios de la restauración arquitectónica en un bien de naturaleza patrimonial. Pero, como ha quedado demostrado a través de las aportaciones de la Bienal y de los debates generados en ella, la des-restauración como acto potencial y de facto hacia el patrimonio puede y debe remontarse más allá de la pionera intervención de eliminación de la actuación historicista neomedieval de la Basílica de Saint Sernin de Toulouse (fenómeno acaecido a partir de 1980 al cuestionarse la intervención estilística de 1845 de Viollet-le-Duc), e interpretarse quizá de modo más ambiguo y a la vez menos arriesgado como la eliminación de cualquier aportación fuera de marcos temporales y creativos que a su vez están delimitados por el prisma con el que la Historia y la Humanidad se quiere acercar al objeto que trata.

Para lograr delimitar y definir tanto el vocablo como las acciones que en él se puedan amparar, sin ánimo doctrinario pero marcando vías prácticas basadas en la experiencia, la III Bienal de Restauración Monumental ha planteado un amplio y constreñido programa que ha desarro- llado una serie de ponencias, comunicaciones y debates llevados a cabo en la biblioteca del IAPH, especialmente adaptada para la ocasión. El programa se ha completado con las visitas a la sede del Instituto, al Real Alcázar, la Iglesia del Salvador y la Catedral de Sevilla. Hay que destacar la participación internacional de los ponentes, con especial incidencia en los procedentes de Italia, siempre un referente en el campo de la conservación, así como la muestra de experiencias de nuestro ámbito local, destacando los conflictos históricos para definir las des-restauraciones en intervenciones contemporáneas, como en el caso del Palacio de San Telmo de Sevilla, que centró el debate de la conferencia inaugural de la Bienal. Los bloques en los que las comunicaciones se agruparon, abarcando desde la definición del término en las últimas décadas a la compatibilidad de materiales y técnicas, los concernientes a las relaciones entre los actos de des-Restauración y la legislación sobre el patrimonio histórico español o los principios más teóricos -especialmente incisivos en los campos de la reivindicación de la Arquitectura y de su control histórico y jurídico-, no hicieron sino manifestar la heterogeneidad resultante del enfoque multidisciplinar desde el que se aborda el patrimonio monumental.

La eterna discusión acerca de la necesidad de entender como un acto creador la intervención arquitectónica sobre el patrimonio y la necesi- 
R Las ponencias, comunicaciones y debates de la Bienal se han desarrollado en distintos espacios del IAPH / JAVIER Romero, IAPH

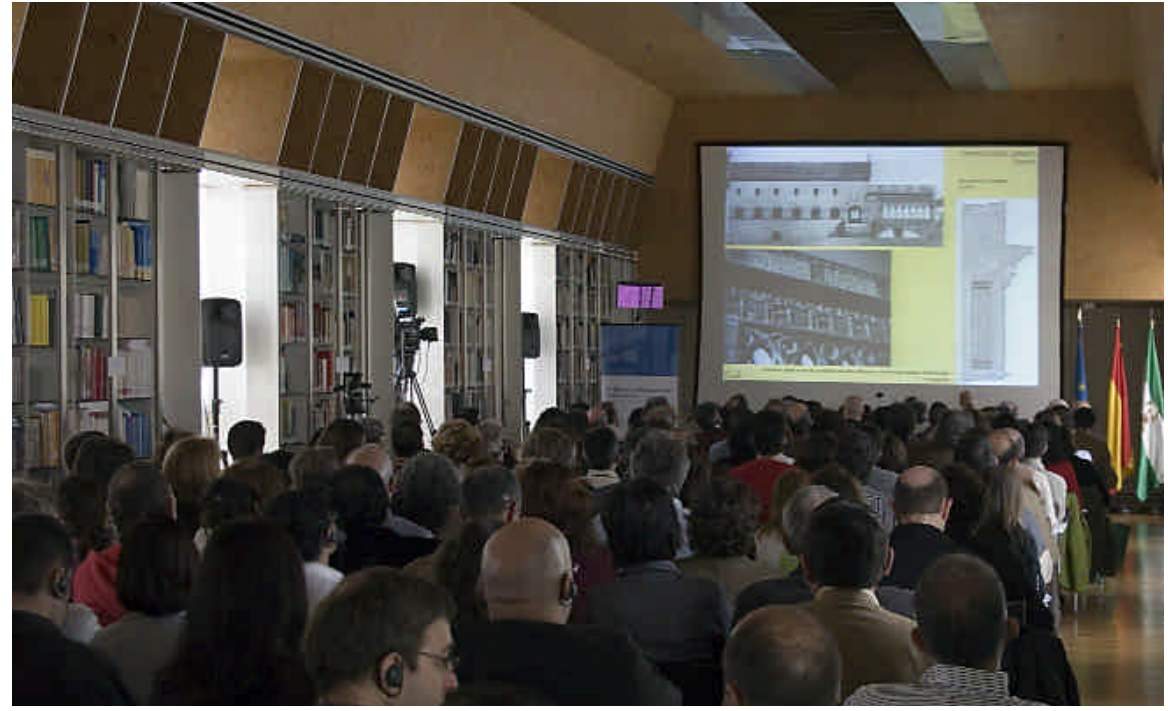

dad de restringirla no sólo por las vías del conocimiento y de la realidad del objeto, sino basándose en legislación útil y restrictiva, conllevó una vez más enérgicas reacciones a lo largo de la mesa redonda celebrada en la jornada de clausura. Debate que puso de manifiesto la inoportunidad muchas veces de la ley para solventar los problemas más inesperados de la conservación y, por otro lado, la necesidad de adaptar en su praxis soluciones al patrimonio dentro de una arquitectura cada vez más carente de la genialidad creativa. La disparidad de trabajos de restauración y conservación que se llevan actualmente a cabo ante la demanda social de estos servicios y su ejecución desde ámbitos profesionales y experiencias limitadas han multiplicado manifiestamente esta pluralidad muchas veces deficitaria.

Tras las jornadas de la Bienal se ha iniciado el difícil camino de la redacción de las conclusio nes finales estructuradas en bloques temáticos que se publicarán junto a las experiencias y reflexiones recopiladas en las ponencias y comunicaciones. Este objetivo final de difusión ha sido y será sin duda germen de estudios y fuente de experiencias a la vez que fruto de reflexiones críticas venideras.
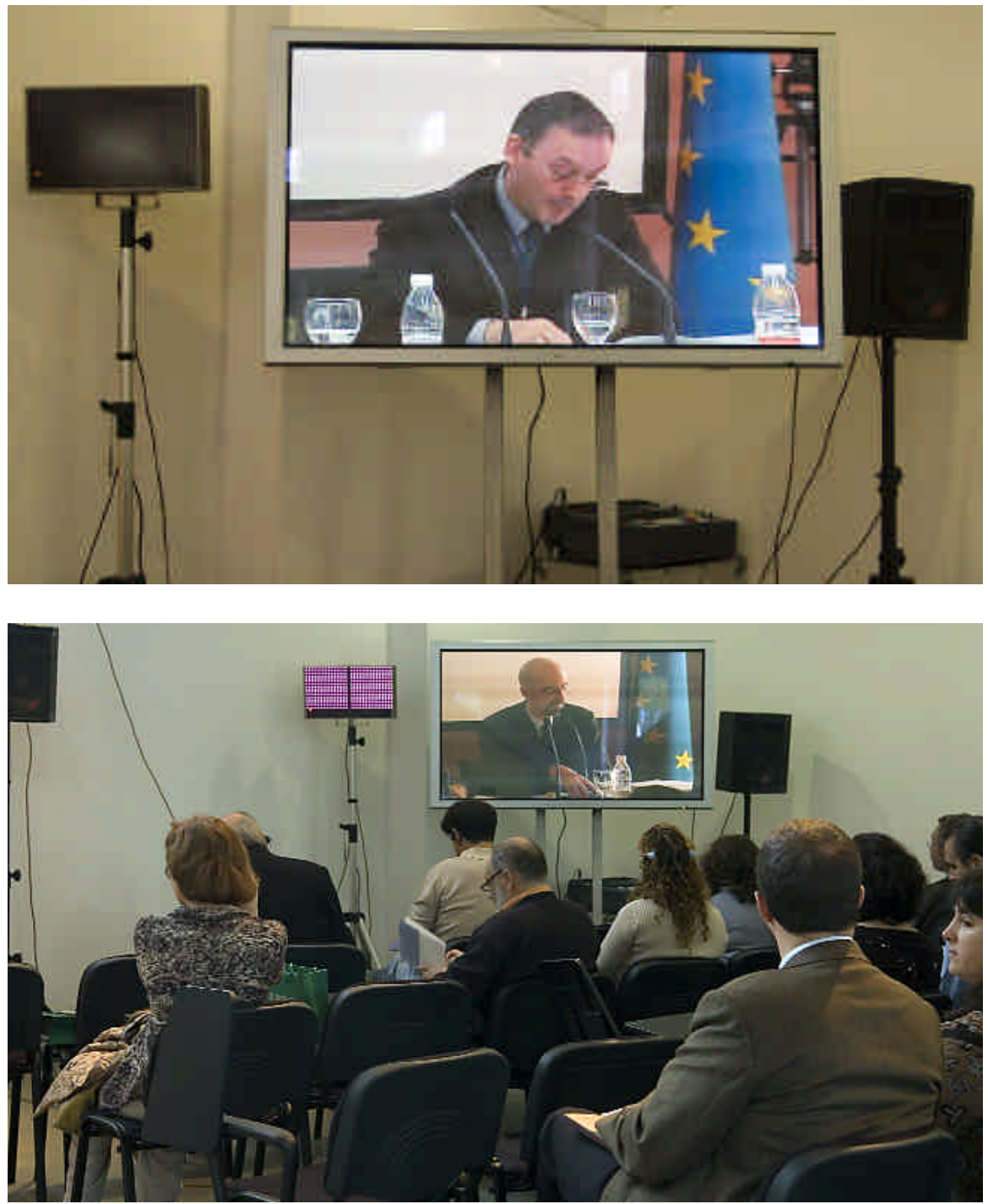